\title{
Efectos de la administración de lactobacilos sobre la flora intestinal en lactantes tratados con antibióticos de amplio espectro
}

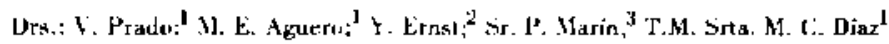

\begin{abstract}
In 25 intants with brosd spertrum antimir-robıal therapy A Anyicillin IM. IV or per usi we studied the ponsibility ot

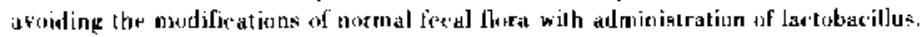

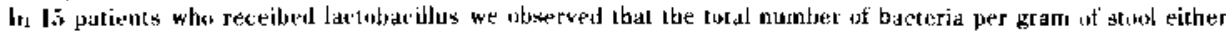
imerased un was not mestified. He did neot see candida uvergrowill.

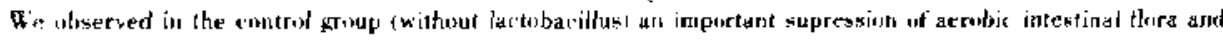

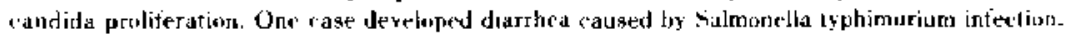

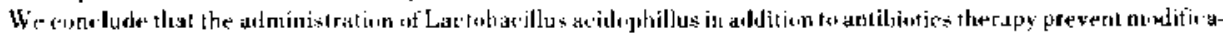

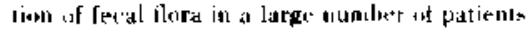

Cada día se ohtienen mayures conorimientus acerce de los roles biolígicos beneficiossos. que cumplen las diferentes bacterias que componen la flera intestinal comensal, pur ejemplo: sintesis de vitamina $\mathrm{K}$, proteccinin de sobre infercinin por bacterios patogenos. En este ültimo aspec.1o se le ha asignado un papel importante a la presencia de lartobacilos, y es asi como desde antiguo se han observado los efectus positivos que se sbtienen eon la administracien de lactobacilos. tanto en la prevencion de infeccinnes intestinales como en el restablecimiento de la flura comensal alteradu(3, $(2)$.

El mecanismo intimo que explica estus efectos no eálá bien esclarecido y algunos autures lo atribuyen a la acción de la Lactocidina. Esta sustancia con propiedades antibacterianas selectivas, actuaria inhibiendo el desarrollo excesivo de algunas bacterias comensales. ejerciendo asi un efecto regulador. ${ }^{(3)}$

Es un fenómen, ampliamente comocido que la administracicin de antibiótic'us de amplis, espectro. provica trastornos de la Mora comensal intestinal con diversos gradus de intensidad rlinica, que se pueden traducir en diarrea, ya se a través de la excesiva proliferarion de algunos comensales o

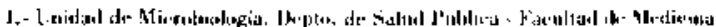

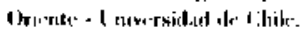

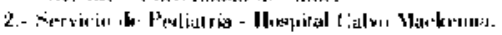

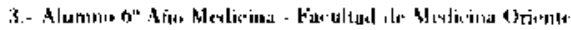

favoreciendo la invasión de enteropalógenos, 14 . 1 मे

El propisito de la presente investigación fue objetivar si la asociación de lactobacilus, utilizando una cepa resistente a los antimicrobianos (Antibiophillus ${ }^{\prime}$ r Larochè, junto a la administración de antibióticos de amplio espectro, puede evitar o disminuir la alteración de la flora intestinal.

\section{MATERIAL Y METODO}

Se consideraron para el estudio 25 pacientes internados en el Hospital Calvo Mackenna. por diversas patologías y que requerían el usu de antibióticos de amplio espectro, en especial Ampicilina y Gentamicina. Las edades lluctuaban entre 11 días y 21 meses y estaban sometidos a una dieta similar.

En forma randomizada, a un grupo de 15 pacientes se les asocio Lactobacilus acidophilus en rantidad de un billin de bacilos liofilizados ( 1 gr.). por dia en una dosis oral, ladiciunada a la lechel durante 5 días.

Los restantes 10 pacientes constituyeron el grupe control.

A rada paciente se le tumaron muestras seriadas de deposicioth, al I. - 3." - 5." y 7. " dia de tratamienter efectuandurecuenl" y tipificarion de bater rias aecobias y lomges. 
Diluciones seriadas de las muestras, fueron sembradas en Agar lactosado, Agar sangre, Agar SS y Saboureaud, efectuando incubación a $37^{\circ} \mathrm{C}$, con lecturas a las 18 horas para el recuento bacteriano. Para el estudio de hongos se incubó a $25^{\circ} \mathrm{C}$, con lecturas a los 14 y 21 días.

Los lactobacilos administrados no influyen en los recuentos, pues tienen otros requerimientos.

\section{RESULTADOS}

En la tabla N." 1 se detallan los diagnósticos clínicos de los pacientes incluidos en el estudio que motivaron la indicación de terapia antimicrobiana.

\section{Tabla N. ${ }^{\circ} 1$}

Efecto de lactobacilos sobre flora intestinal en lactantes tratados con antimicrobianos Patología de base

\begin{tabular}{lcc}
\hline & \multicolumn{2}{c}{ Grupo de observación } \\
\cline { 2 - 3 } Diagnóstico clínico & \multicolumn{2}{c}{$\begin{array}{c}\text { con } \\
\text { lactobacilolactobacilo }\end{array}$} \\
\hline Bronconeumonía & 12 & 6 \\
Bronconeumonia + Otitis & 0 & 1 \\
Broncuneumonfa - Ontalitis & 0 & 1 \\
Pleuroneunonia & 1 & 0 \\
Bronquitis aguda & 1 & 0 \\
Septicemia & 1 & 1 \\
Meningitis purulenta & 0 & 1 \\
\hline Totat & 15 & 10 \\
\hline
\end{tabular}

En la tabla N." 2 aparecen el tipo y vía de administración de los antimicrobianos utilizados en los dos grupos de observación.

\section{Tabla N ${ }^{\circ} 2$}

Efecto de lactobacilos sobre flora intestinal en lactantes tratados con antimicrobianos Tipo y Vía Administración

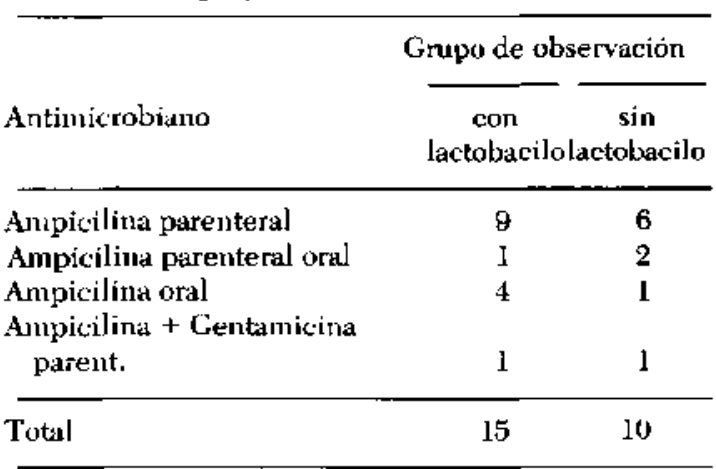

En la tabla N." 3 se comparan las variaciones promedio del número de bacterias por gramo de deposición en el curso del tratamiento antibiótico en los dos grupos de estudio.

\section{Tabla N. 3}

Efecto de lactobacilos sobre la flora intestinal en viños tratados con antimicrobianos

Promedio de recuento bacteriano por Gr/deposición

\begin{tabular}{|c|c|c|c|}
\hline \multirow[b]{2}{*}{ Grupo de ubservación } & \multicolumn{3}{|c|}{ Recuento promedio $\times 10^{6}$} \\
\hline & $\mathrm{n}$ & $1 .^{\circ} \mathrm{dia}$ & $5 .^{\circ}-7 .^{\circ} \mathrm{d} a$ \\
\hline AB mis Lactobacilo & 15 & 4.104 & $8.964^{1}$ \\
\hline AB sin Lactobacilo & 10 & 3.733 & $864^{2}$ \\
\hline
\end{tabular}

Nota: $(1)-(2) \mathrm{t}=6.54 \mathrm{P}<0.001$

En la tabla N. 4 se analizan los cambios individuales observados en la flora intestinal en los pacientes estudiados.

\section{Tabla N.0 4}

Efectos de lactobacilos sobre flora intestinal en lactantes tratados con antimicrobiarios

Variaciones del recuento bacteriano por GR/deposición

\begin{tabular}{lcc}
\hline & \multicolumn{2}{c}{ Grupo de observación } \\
Variación & Con lactobacilo Sin lactobacilo \\
\hline Aumento & $9 / 15$ & $2 / 10$ \\
Mantención & $1 / 15$ & $0 / 10$ \\
Disminución & $5 / 15$ & $8 / 10$ \\
\hline
\end{tabular}

En la tabla N. ${ }^{\circ 5}$ se compara la proliferación de levaduras a lo largo del tratamiento antibiótico en ambos grupos de observación.

Tabla N.95

Efecto de lactobacilos subre flora intestinal en lactantes ratados con antimicrobianos

Promedio del recuentu de levaduras por GR/deposición

\begin{tabular}{|c|c|c|c|}
\hline \multirow[b]{2}{*}{ Grupo de observación } & \multicolumn{3}{|c|}{ Recuento promedio $\times 10^{4}$} \\
\hline & $\mathrm{n}$ & 1." día & $5 .^{\prime \prime}-7 .^{\prime \prime}$ día \\
\hline (3) & 15 & 1.46 & $3.13^{1}$ \\
\hline AB sim Lactoleicilo & 10 & 1.66 & $32.44^{2}$ \\
\hline
\end{tabular}

Noti: $(1)-(2) \mathrm{t}=1.23 \mathrm{~N} . \mathrm{S}$. 
En el gralica N." I se observan las variaciones en cantidad por gramonde deposicion de las bacterias aerubias consileradas romer marcalores de thera intestimal. duranto el turso del fratamiento antimicrobjatuo en el grupo de pacitates pue recibia lac:tolyadilos.

PRCAENTES CON ANTIEIGTLOO Y LaCTOBACILOS
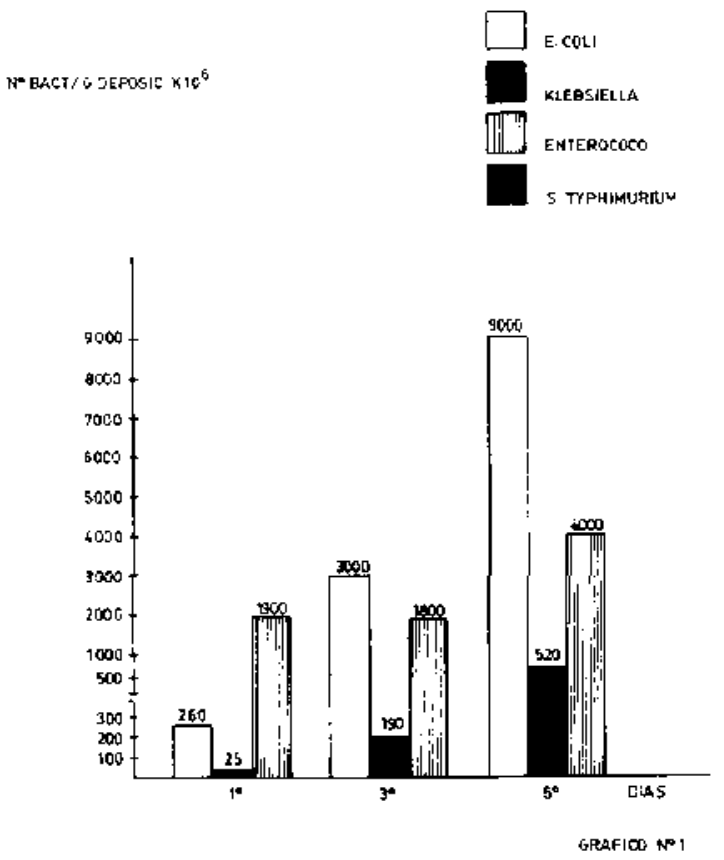

En el gráfico N." 2 se observan las variaciones en cantidad de las bacterias aerobias comensales del intestino y de enteropatógenos durante la terapia antibiótica, en el grupo de pacientes que no recibió lactobacilos.

\section{COMENTARIOS}

Entre los antimicrobianos, considerados responsables de causar desequilibrio de la ecología intestinal traducible en alteraciones del tránsito, que van desde diarrea simple a enterocolitis necrotizante pseudomembranosa, se encuentran principalmente Lincomicina, Clindamicina, Ampicilina, y con menos frecuencia Penicilina y Cotrimoxazol. ${ }^{\text {(6) }}$

Nos pareció interesante considerar para nuestro estudio, lactantes tratados con Ampicilina, antimicrobiano de amplio uso en pediatría para objetivar los cambios que produce en la composición de la flora intestinal (tabla N. ${ }^{\nu} 2$ ) y ver asimismo el efecto de la asociación de lactobacilos en estos pacientes.
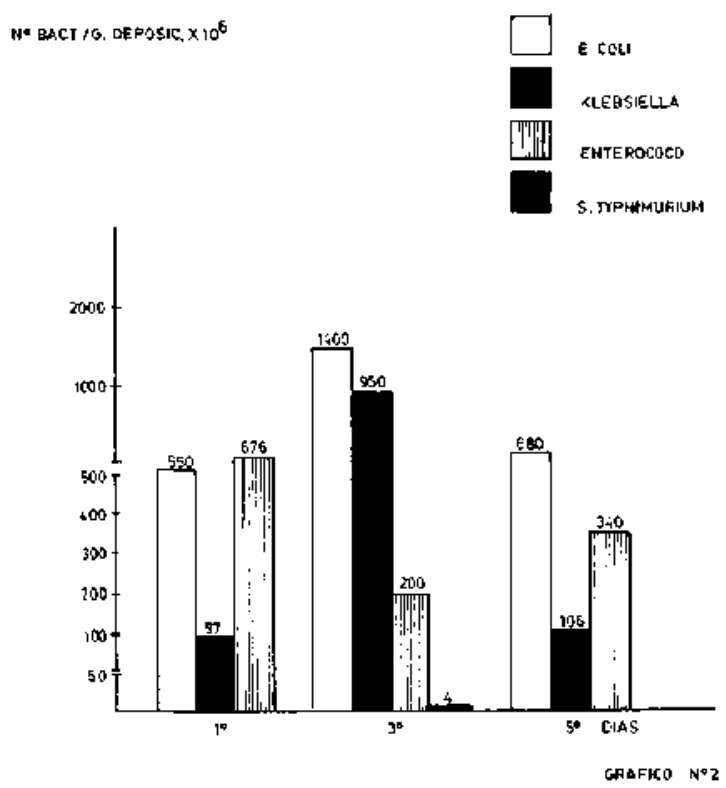

Ha sido demostrado que la flora bacteriana comensal, tiene una composición bastante compleja y está formada por numerosas especies bacterianas, el mayor porcentaje de ellas corresponde a anaerobios estrictos, principalmente bacteroides y bifidobacterium y aproximadamente el $1 \%$ está formado por bacterios anaerobios facultativos como $\mathrm{E}$. coli. KJebsiella y enterococos (i) Por ser estas tres últimas especies bacterianas de fácil cultivo en condiciones aerobias y por constituir los componentes más constantes de la flora intestinal humana normal. las hemus considerado como marcadores para evaluar cambios en la composición de la flora bacteriana del intestino.

Los datos obtenidos de nuestros estudios nos muestran que en el grupo control, que recibió soilo antibióticos, se produjo una supresión importante de la camtidad de bacterios aerobios, en el curso de 5 a 7 dias de tratamiento.

En contraste, en el grupo de pacientes a los cuales se les asoció lactobacilos, se observó un franco aumento del recuento de bacterias por gramo de deposición expresado tanto en el promedio como en forma individual, con significación estadística (tablas N." 3 y 4). Se estableció que los lactobacilos no inciden en los recuentos, porque necesitan medios de cultivo diferentes, deberíamos entonces deducir que la adición de lactobacilos estaría facilitando de algún modo la proliferación de estas bacterias. Los recuentos alcanzados están siempre dentro de lo observado en individuos normales. ${ }^{8 r}$ 
En el grupo de pacientes que recibió lactobacilos se apreció junto a la preservación y/o proliferación de la flora bacteriana aerobia nurmal, una disminución de la multiplicación de levaduras, sin llegar a ser éstas diferencias esladísticamente significativas respecto al grupo control. Este hecho tiene proyecciones interesantes, ya que a través de lactobacilos también se podría evitar la proliferaciún de otros comensalea potencialmente patúgenos como Clostridium difficile, anaerubio capaz de producir una enterotoxina con propiedades citutíxicas, el cual ha sido sindicado como responsable de cuadros de enterocolitis necrotizante en pacientes tratados con antibióticos. Este bacterio al existir en baja proporcion no provocaría daño porque la escasa cantidad de tuxina liberada no alcanzaria a producir un efecto biológico importante, 19,15 ,

En relación a la proporción entre las bacterias comsideradas como parámetros marcadores, se observí en el grupo que recibió lactobacilos un aumento oreferente de E. coli sin aparición de enterepatingenos; en cambio en el grupo sontrol uno de lus pacientes se infectís con Salmunella typhimurium (gráficos $\mathrm{N} . " \mathrm{l}$ y 2 ), y presentó deposiciones alteradas a partir del $3^{\prime \prime}$ dia de antibiótico.

Comentario aparte merece el hecho que en la mayoría de los casos incluidos en nuestro estudio el antimicrobiano se administrí por vía parenteral, luego no súlo los antibiólicos orales desequilibran la flora intestinal, hecho que también ha sido corroborado en animales de laboratoriw. ${ }^{6 j}$

\section{CONCLLSION}

Los resultados observados permiten concluir que lid asociacioin de lactobacilos (Antibiophillusi' $\mathrm{K}$, Larochel a la administracioin de antibióticos de amplio espectro logra evitar en un número importante de casss la alteracioun tantro cuantitativa como cualitativa de: la flora intestinal normal.

\section{AG:RADECIMIENTOS}

Agradecemos al Dr. Luis hodriguez su ayuda en el análisis estadistico de los dalus obtenidos.

\section{RESUMEN}

En 25 lactantes sometidos a tratamiento con antibióticos de amplio espectro (Ampicilina parenteral u oral). se estudió la posibilidad de evitar las alteraciones de la flora intestinal normal, adicionando lactubacilos.

En un grupo de 15 niños que recibieron lactrobacilos se observó una preservación o aumento del recuento bacleriano por gramo de deposición, $\sin$ proliferación de levaduras.

En el grupo čntrol ( 10 nin̄ns) que no recibieron lactobacilos, en contraste se observó una supresión importante de la flora aerobia intestinal con aumento del recuenlo de levaduras. En un caso se observó una infeccion enteral intercurrente por Salmonella typhimurium.

Se concluye que la asociación de lactobacilos acidophillus (Antibiophillus' ${ }^{\mathrm{B}}$ ') a la terapia con antibióticus de amplio espectro logra evitar en un número importante de casus la alteración de la flora intestinal.

\section{REFERENCIAS}

${ }^{1}$ Alexusder, J. G. "Truch Bowel Infection Existence. Incidence, Prevention and Treatment, Particularly by a Lactobacillus Acidophillus Preparation. Curr Med. Druge. 8: 3.11, 1967.

2 Ellis, S.; Spratt,J. "Lactobacillus Overgrowth Diet as an Aid in Controlling E. coli Septicemia and Endotoxemia in Cancer Patients, a Case Reported". J. Amer. Geriatr. Soc. J8: 410-15, 1970.

3 Vincent. F. G.; Veontelt H. C., Rultey, R. F. "Antibacterial Activity and Lactobucilus Aridophillus". J. Barteriol 78: 47748.5, 1959.

${ }^{4}$ George, W. La; Sutler, S. M.; Finegold, S. M. "Anumicrobial Agent-induced Diarrhea - a Baclerial Disease". J. lnfect Disease 136: 822, 1977.

S Bartiett. J. G, Chang. T. W; Gurwith, M.; Gorbah, S. L.

"Antibiotic-associared Preudonembranuus Colitis Due 1n Toxin - Producing Clostridia". Vew Eng. J. Med. 298, 1978.

o Georue. W. L; Fulfe, K. D.; Sutter, V. L.; Finegold, S. M. "Diarrhea and Colitis Asseciated with Antimicrubial Therapy in Man and Animals". Aso. J. Clin. Nutr. 32: 251. 1979,

"Crarbuch, S. L. "Intestinal Mieruflura Gastruenteroberg", 60: $1100,1971$.

${ }^{8}$ Fincgold, S. M.: Sutter. V. L. "Fecal Flara in Different Pupulations, with bpecial Reterence to Diet". Am. J. Clin. Nutr. 31: $5116.197 \mathrm{~B}$.

"Larson, II. E.; Price, A. B. "Psendomembranous Culitis l'resence af Clostridia Toxin", Lancet $2 \div 312,1977$. 